\title{
Managing Bigeye Tuna in the Western and Central Pacific Ocean
}

\section{OPEN ACCESS}

Edited by: Sebastian Villasante,

University of Santiago de Compostela, Spain

Reviewed by:

William John Hampton,

Pacific Community (SPC), New

Caledonia

Jennifer Leigh Bailey,

Norwegian University of Science and Technology, Norway

*Correspondence: Dale Squires

Dale.Squires@noaa.gov

Specialty section: This article was submitted to Marine Affairs and Policy, a section of the journal Frontiers in Marine Science

Received: 26 February 2020 Accepted: 06 July 2020 Published: 14 August 2020

Citation:

Post $V$ and Squires D (2020) Managing Bigeye Tuna in the Western and Central Pacific Ocean.

Front. Mar. Sci. 7:619. doi: 10.3389/fmars.2020.00619

\begin{abstract}
Valerie Post ${ }^{1}$ and Dale Squires ${ }^{2 *}$
${ }^{1}$ National Marine Fisheries Service, Pacific Islands Regional Office, Honolulu, HI, United States, ${ }^{2}$ National Marine Fisheries

Service, Southwest Fisheries Science Center, La Jolla, CA, United States
\end{abstract}

The Western and Central Pacific Fisheries Commission (WCPFC) is responsible for managing highly migratory species in the Western and Central Pacific Ocean (WCPO), and has been interested in managing bigeye tuna as stock assessments prior to 2017 indicated that the stock was experiencing overfishing. This paper provides some background on the primary fisheries catching bigeye tuna in the WCPO, describes the various policies within the conservation and management measures adopted by the WCPFC, discusses the effectiveness of such policies, and concludes with some suggestions for future policies for consideration.

Keywords: bigeye tuna, purse seine, longline, western and central Pacific Ocean, bycatch

\section{INTRODUCTION}

The Western and Central Pacific Ocean (WCPO) contains the largest tuna fisheries in the world, with catches in 2018 contributing to 55\% of global tuna catch (Williams and Reid, 2019). Several tuna species are caught in the WCPO including skipjack (Katsuwonus pelamis), yellowfin tuna (Thunnus albacares), bigeye tuna (T. obesus), albacore (T. alalunga) and Pacific bluefin tuna (T. orientalis), and the predominant gear types include purse seine, longline, pole and line and troll.

The Western and Central Pacific Fisheries Commission (WCPFC or Commission) is the regional fisheries management organization (RFMO) responsible for managing highly migratory species in the WCPO. The WCPFC entered into force in 2004 and has the largest area of application (hereafter WCPFC Convention Area) of the five tuna RFMOs. The WCPFC Convention Area covers almost $20 \%$ of the earth's surface and generally encompasses the Pacific Ocean west of $150^{\circ} \mathrm{W}$ to the Asian continent. As of December 2019, the WCPFC is comprised of 26 members, 7 participating territories and 8 cooperating non-members ${ }^{1}$ (collectively referred to as CCMs). The Commission meets annually and, to date, all decisions on conservation and management measures (CMMs) have been made by consensus.

Bigeye tuna has been a stock of particular interest in the WCPO. Although the 2017 stock assessment indicated the stock was not experiencing overfishing and was not overfished, previous assessments indicated that the stock was experiencing overfishing, and the 2014 stock assessment

\footnotetext{
${ }^{1}$ Member to the WCPFC include Australia, China, Canada, Cook Islands, European Union, Federated States of Micronesia, Fiji, France, Indonesia, Japan, Kiribati, Korea, Republic of Marshall Islands, Nauru, New Zealand, Niue, Palau, Papua New Guinea, Philippines, Samoa, Solomon Islands, Chinese Taipei, Tonga, Tuvalu, United States of America, and Vanuatu. Participating territories to the WCPFC are American Samoa, Commonwealth of the Northern Mariana Islands, French Polynesia, Guam, New Caledonia, Tokelau, and Wallis and Futuna. Cooperating non-members to the WCPFC are Curacao, Ecuador, El Salvador, Nicaragua, Panama, Liberia, Thailand and Vietnam.
} 
indicated that the stock was overfished (Harley et al., 2010, 2014; McKechnie et al., 2017). The two primary fisheries in the WCPO that catch bigeye are the deep-set longline fishery, which targets adult bigeye, and the purse seine fishery, which targets skipjack and yellowfin, and catches juvenile bigeye incidentally. The WCPFC has since its inception grappled with reducing fishing mortality for bigeye tuna, and adopted many CMMs aimed at managing and conserving this species of tuna. Since the 2017 stock assessment, the management focus in the WCPFC for bigeye tuna has shifted from reducing overfishing to maintaining average spawning biomass at 2012-2015 levels.

The purpose of the paper is to provide relevant background on bigeye tuna and the longline and purse seine fisheries responsible for significant bigeye tuna extraction in the WCPO, describe the various CMMs adopted by the WCPFC, evaluate the effectiveness of the various CMMs, and provide some recommendations for future consideration. This paper primarily focuses on the scientific side of management and the potential role of incentive-based strategies. We recognize that many factors play a role in multilateral decision-making and that there is an extensive body of economic, game-theoretic, institutional and politics literature available, but detailed discussions of such considerations are beyond the general scope of this paper (Barrett, 2003; Hanich, 2012; Libecap, 2014; Norris, 2015; Barret, 2016). We further recognize that bycatch policies may contain implicit or explicit allocation among CCMs, which may be highly contentious.

\section{BACKGROUND}

Bigeye tuna is an important component of the WCPO tuna catch. In 2018, the provisional catch estimate of bigeye tuna was $142,402 \mathrm{mt}$ and was estimated to be valued at $\$ 780$ million United States dollars (Williams and Reid, 2019). For many years, stock assessments conducted by the Oceanic Fisheries Programe of the Pacific Community (commonly known as SPC-OFP) and endorsed by the Commission's Scientific Committee concluded that WCPO bigeye have experienced rates of fishing mortality above the rate of fishing mortality at maximum sustainable yield (MSY) (Harley et al., 2010, 2014; Davies et al., 2011). The 2014 stock assessment also indicated that the stock was overfished, as the spawning biomass was below the limit reference point (Harley et al., 2014). In 2017, the WCPFC Scientific Committee reviewed a new stock assessment which included a new growth curve and regional structure, and these factors along with estimated increases in recent recruitment contributed to a much rosier outlook on stock status (WCPFC, 2017). The Scientific Committee noted that biomass was now greater than the limit reference point so the stock was not overfished, and that fishing mortality was below fishing mortality at MSY so the stock was not experiencing overfishing. Although the stock status for bigeye tuna improved, the Scientific Committee noted that some regions have large juvenile mortality and recommended that the Commission continue to reduce fishing mortality on juveniles in order to increase stock size (WCPFC, 2017). This change in stock status was surprising to some observers given that some earlier accounts had stressed the failure of the Commission to adopt adequate conservation measures (Hanich, 2012).

Bigeye tuna are predominantly caught by longline or purse seine vessels with those two gear types accounting for $85-90 \%$ of the WCPO bigeye catch each year. From 2014-2018, longline catch of bigeye tuna represented $\sim 45 \%$ of the total bigeye catch while purse seine catch of bigeye tuna was $\sim 43 \%$ of total bigeye catch (SPC, 2019d). Most of the purse seine caught fish are considered juvenile $(\sim 3 \mathrm{~kg})$, while the longline fishery generally catches adult sized fish $(\sim 40 \mathrm{~kg})$ (Abascal et al., 2014; McKechnie, 2014).

Longline vessels in the WCPO target several species of tuna and billfish depending on the area fished, and set type. Longline fleets-from Japan, Korea, Taiwan, and China (along with smaller localized fleets out of Hawaii, Fiji, etc.) - target bigeye and yellowfin tuna for sashimi markets. Longline vessels have operated in the WCPO since the early 1900s, and numbers of vessels have generally fluctuated between 3,000-6,000 vessels for the last 30 years (Williams and Reid, 2019). The number of longline vessels and overall catch peaked in the early 2000s, and both vessel numbers and bigeye catch have subsequently declined over the past 15 years. The WCPO longline tuna catch from 2018 was valued at over $\$ 1.7$ billion United States dollars, with the value of the longline bigeye catch (\$660 million United States dollars) accounting for nearly $40 \%$ of the total (Williams and Reid, 2019).

Purse seine vessels in the WCPO generally target skipjack and yellowfin tuna, but also catch several other species, including juvenile bigeye tuna [fish under $103 \mathrm{~cm}$ (Farley et al., 2017)]. Since the inception of the purse seine fishery in the WCPO in the 1970 s, the number of vessels as well as the total catch of tunas have steadily increased. In 2015, there was a record high of 308 purse seine vessels fishing in the WCPO purse seine fishery (excluding the domestic purse seine fisheries in Philippines, Indonesia and Vietnam) and in 2014, there was a record high WCPO purse seine catch of 2,059,008 $\mathrm{mt}$ of tunas (Williams and Reid, 2019). The WCPO purse seine catch from 2018 was valued at over \$3.4 billion United States dollars (ex-vessel), which represents over $50 \%$ of the total ex-vessel value of the 2018 WCPO tuna catch (Williams and Reid, 2019).

Unlike the longline fishery, the WCPO purse seine fishery does not target bigeye tuna, but catches juvenile bigeye tuna incidentally. Purse seine vessels set large nets that act as big areas that confine the tuna, which are then pursed into a smaller sized net and fish are then scooped (brailed) onto the vessel and put immediately into the fish hold for freezing. In the WCPO, vessel operators generally engage in two types of sets; unassociated sets or sets on free schools of yellowfin and skipjack tuna, or associated sets or sets made on fish aggregating devices (FADs), which can be naturally or man-made floating objects. Up until the mid-1990s, purse seine vessels made the majority of their sets on free schools and on naturally floating objects such as logs. This pattern changed in the mid-1990s, when purse seine vessels started to increasingly rely on man-made FADs. In 2018, the proportion of unassociated sets was $64 \%$ and the proportion of associated sets was 36\% (Williams and Reid, 2019) in the fishery as a whole, however, some national fleets rely more on FAD sets 
than others due to economic factors. FAD sets tend to have a higher catches in weight per set so although associated sets only made up $36 \%$ of the sets, catch from associated sets made up 51\% of the total catch (Williams and Reid, 2019).

FAD sets not only have higher catches per set than sets on free schools, but also improve the odds that a purse seine vessel will have a successful set (fewer "skunk" sets - which means no catch). Although the opportunity to use FADs increases the economic success of a purse seine vessel, FAD sets tend to result in catches of smaller-sized fish, greater bycatch, and catches with higher proportions of bigeye tuna as compared to free-school or unassociated sets (Dagorn et al., 2012). Purse seine-caught bigeye tuna prior to the 1990 s represented $30 \%$ or less of the total WCPO bigeye catch, and since the 1990s increased to represent 30-49\% of the total WCPO bigeye catch (SPC, 2019d). Although, the purse seine fishery catches less bigeye by weight than the longline fishery, the purse seine fishery catches far greater numbers of small bigeye, and this removal of small bigeye has effects on the level of maximum sustainable yield (Davies et al., 2011; Harley et al., 2014).

Juvenile bigeye can be difficult to distinguish from juvenile yellowfin, and obtaining accurate estimates of purse seine-caught bigeye tuna has proved challenging. It has been found that fishermen generally underestimate catch of bigeye tuna on their logbooks, and bigeye is commonly misreported as yellowfin or skipjack (Lawson, 2014). CCMs annually submit catch data to the WCPFC for their fisheries and in reporting catches by their purse seine fleets, most CCMs do not make adjustments from what is reported by vessel operators in logbooks (i.e., the information is unadjusted for what is known to be underestimates of bigeye tuna catch). SPC-OFP, which is the science and data provider to the WCPFC, not only compiles reported catch by members, but also uses observer data on catch by species and size to estimate each member's purse seine bigeye tuna catch. Cannery data has also been used by some CCMs to better estimate bigeye tuna catch from purse seine vessels as canneries produce reports on quantities of fish accepted by weight and species. Canneries may pay different prices for fish depending on species and size class, and cannery estimates are believed to be relatively accurate for larger sized bigeye tuna ( $>3 \mathrm{~kg}$ ). However, there is little incentive for canneries to accurately identify smaller-sized fish, as there tends to be no price differential between species for the smallest sized fish. Most small sized $(<2 \mathrm{~kg})$ bigeye tuna, yellowfin tuna, and in some cases skipjack tuna, are mixed together and reported by the canneries as a mixture or as purely skipjack or yellowfin tuna.

\section{APPLICATIONS OF POLICIES}

Reducing fishing mortality - especially on juvenile bigeye has been a priority for the WCPFC since the Commission's establishment, and the WCPFC adopted its first CMM for bigeye and yellowfin tuna in 2005. As of June 2020, the CMM for bigeye, yellowfin and skipjack tuna has been revised and replaced nine times. The most current version, adopted in December 2018, is CMM 2018-01. Most changes to the original measure have been fairly minimal, however, greater changes occurred in the CMMs adopted in 2008, 2014, and 2017 roughly concurrent with when changes were made to the management objectives for bigeye tuna. CMM 2018-01 is effective through February 2021, and the Commission is expected to work on a replacement measure at its 2020 annual meeting. The Commission adopted a biomass-based limit reference point of $20 \%$ of unfished spawning stock biomass in 2012, and the most recent objective for bigeye tuna management comes from paragraph 12 of CMM 2018-01 which states, "Pending agreement on a target reference point the spawning biomass depletion ratio $\left(\mathrm{SB} / \mathrm{SB}_{\mathrm{F}=0}\right)$ is to be maintained at or above the average $\mathrm{SB} / \mathrm{SB}_{\mathrm{F}=0}$ for $2012-2015$.

The WCPFC has adopted a number of restrictions for the purse seine fishery. The input or effort-based restrictions used by the WCPFC to manage the purse seine catch of bigeye tuna have included prohibiting the use of FADs during certain time periods, and limiting the number of FAD sets by each CCM over a year. These effort-based restrictions (process standards) are all examples of command-and-control policies (regulatory measures that mandate specific vessel behavior through limits or standards on technology, process of production, or the catch and bycatch performance) and the FAD limits have primarily been flaggedbased (counting against the limit of the CCM to which the vessel is flagged or chartered) though there have been some zonebased exemptions some years for small island developing states (SIDS). The WCPFC has also adopted a "full"-retention policy for tropical tunas, which could be construed as incentive or marketbased. The retention policy, adopted as a new provision in 2008, requires vessels to retain all bigeye, yellowfin and skipjack tunas caught except in some limited circumstances ${ }^{2}$. As mentioned previously, canneries pay different prices by species and size, and as prices for small fish are much less than prices for big fish, this retention policy was adopted as stated in paragraph 27 of CMM 2008-01, "to create a disincentive to capture small fish and to encourage the development of technologies and fishing strategies designed to avoid the capture of small bigeye and yellowfin tuna..." Full retention also creates an indirect or opportunity cost of foregone catches of larger sized tunas. It is not clear full retention has ever worked or was actually adopted with the cited reasoning being the main objective of the policy.

For the longline fishery, the Commission has used catch limits (performance standards) to conserve and manage bigeye tuna catch. Initially, CCMs that historically caught over 2,000 mt of bigeye were not to exceed either the average annual catch from 2001-2004 or the catch in the year 2004 (at the discretion of the CCM), and any CCM that historically caught less than 2,000 $\mathrm{mt}$ were not to exceed 2,000 mt. As the Commission later believed more reductions were needed, CCMs that caught greater than $2,000 \mathrm{mt}$ were required to reduce catches by anywhere from 10 to $30 \%$ starting in 2009, and many of these same CCMs were required to reduce catches further in 2015. For several CCMS, longline catches had declined in years leading up to the adoption of CMM 2008-01 so the reductions were not necessarily limiting.

\footnotetext{
${ }^{2}$ The exceptions for the catch retention policy are (1) if on the final set of the trip, there is insufficient well space to accommodate all fish caught on the set, (2) when the fish are unfit for human consumption for reasons other than size, and (3) when serious malfunction of equipment occurs.
} 


\section{EVALUATING PERFORMANCE}

Over time, the WCPFC's objectives for bigeye tuna have shifted in part due to changes in stock status as well as due to progress the Commission has made in developing reference points for bigeye tuna. In this section, we will evaluate the three objectives for bigeye tuna from 2008-2011, 2012-2016, and 2017-2020. We will also evaluate the effectiveness of some of the various types of policies undertaken in the different CMMs over time.

In CMM 2008-01, the WCPFC's objective for bigeye tuna was to reduce bigeye fishing mortality by at least $30 \%$ from the annual average from 2001-2004, or 2004. Despite reductions in longline limits, catch retention and seasonal FAD closures, annual fishing mortality for both adult and juvenile bigeye from 2009-2012 remained at or above the levels from 2001-2004 (McKechnie et al., 2017).

In CMMs adopted from 2012-2016, the WCPFC's objective for bigeye tuna was to reduce fishing mortality for bigeye tuna to a level no greater than $F_{\mathrm{msy}}$. SPC investigated the potential effectiveness of the various CMMs (CMM 2013-01, CMM 2014-01, and CMM 2015-01) on the bigeye tuna stock and in general, found that fishing mortality would only remain below $F_{\mathrm{msy}}$ under optimistic fishing scenarios where the measure worked as intended and the FAD closures remove FAD sets from the fishery (SPC, 2014, 2015, 2016). The 2014 stock assessment also found that recent (2008-2011) fishing mortality was greater than $F_{\text {msy }}$ (Harley et al., 2014). However, as noted above, the 2017 stock assessment had a number of changes that led to very different conclusions in which recent fishing mortality (2011-2014) was less than $F_{\text {msy }}$.

As a result in the shift in stock status, the WCPFC modified its objective for bigeye in CMMs 2017-01 and 2018-01 to read "Pending agreement on a target reference point the spawning biomass depletion ratio $(\mathrm{SB} / \mathrm{SBF}=0)$ is to be maintained at or above the average SB/SBF $=0$ for 2012-2015." SPC has conducted a number of analyses to evaluate the potential for CMM 2018-01 to achieve its objectives for the three stocks of tropical tunas including bigeye tuna (SPC, 2017, 2018, 2019c). In general, achieving the objectives for bigeye tuna are strongly influenced by the recruitment scenario in that scenarios with recent recruitment tend to achieve the spawning biomass depletion ratio objectives while scenarios using long-term recruitment indicate that the objective is not likely to be met (SPC, 2018, 2019c). The analyses also evaluate varying levels of effort and compliance such that maintaining average effort levels from 2013-2015 result in slightly higher levels of spawning biomass in 2045 than an optimistic scenario and a pessimistic scenario (SPC, 2018, 2019c). A new stock assessment is being conducted in 2020, and results from that stock assessment should help inform whether the current objectives are being met.

Longline catches of bigeye tuna have declined over time, and CCMs have collectively been successful in reducing longline catch of bigeye tuna. However, it is difficult to determine whether the decline in bigeye catches in the longline fishery is due to the restrictions imposed by WCPFC members or their respective domestic fleets or if other factors, notably market forces, have played a larger role in the decline. As noted above, longline fleets for some CCMs had been declining before CCM 2008-01 came into effect and so though several fleets had significant reductions from historical levels, some CCMs were easily able to ensure their catches were below their limits without any active management. As these same CCMs with limits have consistently stayed well under their bigeye catch limits since the adoption of catch limits in 2008, their reductions in catch have offset overages by other CCMs with limits as well as increases by CCMs that are not limited. Longline effort in the core area of the of tropical WCPFC longline fishery was higher from 2011-2015 than levels in 2000-2004, but catch and catch per unit effort (CPUE) have been declining over time. Declines in longline effort may also be attributed to other factors such as rising operating costs, decreases in market prices, and increased regulation (Miyake, 2007). Although there have been significant declines in bigeye catch over time, the fishery impact of the longline fleet has only declined slightly over the past 10 years.

Reducing bigeye mortality in the WCPO purse seine feet has also been challenging and the primary mechanism for constraining bigeye catch has been a seasonal FAD fishing/setting prohibition period where vessels are not allowed to set on FADs. The initial period was for 2 months in 2009 and then 3 months from 2010 to 2012. From 2013 to 2017 CCMs had the option to use an additional 4-month of FAD closure or reduce their total FAD set number below a certain level. From 2018-2020, CCMs have a 3-month FAD closure as well as a 2-month FAD closure on the high seas. While not ceasing completely due to a number of exceptions, the catches of bigeye tuna by purse seine vessels decreased dramatically during the FAD closure months, while in general CPUE of skipjack and yellowfin only slightly decreased below average in some months of the 2014 and 2015 closure (Pilling et al., 2013; Williams and Terawasi, 2016). The fishery has experienced classic "effort creep" (productivity growth) over time with increased catchability as well as increases in the number of sets per day over time (Tidd et al., 2015). Since 2009, the number of unassociated sets has nearly doubled from levels in 2000-2004. The average annual number of FAD sets initially remained similar to those from 2006-2009, but declined around $12 \%$ from 2015-2018 (SPC, 2019a).

CMMs 2014-01, 2015-01, and 2016-01 contained a footnote whereby if a CCM could show that their bigeye tuna catch levels had dropped to 55\% of its 2010-2012 levels, then that CCM did not have to apply the complete FAD prohibition on the high seas in 2017. After some controversy, several CCMs were found by the Commission to have met this requirement in 2016 and stated that they would be applying this exemption in 2017 (WCPFC, 2017). A few CCMs achieved these reductions through attrition in their fleets unrelated to any efforts to decrease their own bigeye catch, but since the passage did not have any limitations on how those reductions were made, they were still able to apply the exemption. A few CCMs worried that CCMs that applied the exemption as written in CMMs 2014-01 and 2015-01 could result in high bigeye catch due to unlimited FAD sets on the high seas (WCPFC, 2017). The Commission thus adopted a revised footnote in CMM 201601 in an attempt to limit the bigeye catch from unlimited FAD sets on the high seas by adding a provision that CCMs need to ensure that their bigeye levels remain under the limits needed to achieve 
the exemption, but it was agreed that this is difficult to monitor in a timely fashion due to issues noted above with estimating bigeye catch in the purse seine fleet (WCPFC, 2017).

The WCPFC has adopted one incentive-based policy, the above cited full retention policy for small tropical tunas. The retention policy was adopted in the hopes that retaining small fish would be a disincentive for vessels (due to the costs of lower revenues from lower prices with smaller fish and foregone revenues from foregone catch) and this would induce technological or behavioral responses to avoid catching small fish. The full retention policy has led to declines in discards, and WCPO purse seine discard rates fell from $\sim 3 \%$ of estimated catch before the catch retention requirement went into effect to $2 \%$ of estimated catch after the catch retention requirement came into effect (Chan et al., 2014, SPC, 2019b). Although the retention policy has led to decreases in discards, it is unclear whether this has created any disincentives for fishermen to actually catch small tuna and perhaps could be an area of future study. Canneries may pay low prices for small fish, and it would be interesting to investigate whether this has led to vessels retaining the fish for sale rather than changing their behavior to avoid small sized fish. In times of especially high ex-vessel fish price (e.g., in excess of $\$ 2,000 \mathrm{USD} /$ ton) - operators will catch and land as much small fish as the market demands (R. Clarke, pers.com.). The direct costs of a longer trip could also exceed the incremental increase in revenue given the high cost of fishing days.

\section{SUGGESTIONS FOR CONSIDERATION}

In December 2018, the Commission adopted CMM 2018-01, which is set to expire in February 2021, and a new measure will need to be renegotiated in December 2020. This section discusses various alternative policies that could be considered in managing bigeye tuna. Some of these ideas could be implemented by WCPFC, whereas others may be beyond the scope of WCPFC, but could be supported by members themselves, regional groups such as PNA, or even by consumer groups.

\section{Adopting a TAC}

The Commission may consider in a more material way adopting a total allowable catch limit (TAC) for bigeye tuna, which could help ensure that the total catch of bigeye from all its fisheries would be within a level that would meet its objectives. Although the Commission has adopted limits for some CCMs, it has not set limits for all CCMs nor has it set an overall TAC. In the longline fishery, this lack of limits on all CCMs allows some SIDS to expand their catch histories, but could potentially be problematic if increasing catches eventually lead to overfishing. The Commission tasked itself in paragraph 44 of CMM 2018-01 to adopt a longline limit for bigeye tuna on the high seas by 2020 , but as of June 2020, this has yet to occur. The Commission can estimate levels-by general size class and adopting an overall TAC within these levels could help to ensure the overall conservation objectives could be reached.

Some of the tensions amongst Commission CCMs in adopting limits are how to divide the conservation burden between the various fisheries that catch bigeye at different life stages. As mentioned previously, the purse seine fishery primarily catches juvenile bigeye whereas the longline fishery primarily catches adult bigeye. Although removals by both fisheries impact the size of the spawning stock biomass and the maximum sustainable yield for the stock, catches-on a by-weight basis-of the relatively younger bigeye from the purse seine fishery have a much greater impact than the relatively older bigeye in the longline fishery (McKechnie et al., 2017). The WCPFC has thus far tried to limit both the purse seine and longline fishery sectors, but could consider focusing its efforts more heavily on the purse seine sector as purse seiners have a greater fishery impact with their catch of juvenile bigeye particularly in the tropical regions and the purse seine fishery is not targeting bigeye, but catching them incidentally (McKechnie et al., 2017). The WCPFC could consider dividing the overall limit by fisheries based upon fishery impact, and could extend this to a market-based scheme where there could be transfers between fisheries-when needed or deemed appropriate though any allocation either zone-based or flag-based is likely to be contentious.

Longline catches in the WCPO have declined since 2004, but allocations may not necessarily be efficient as some CCMs do not fully utilize their quotas whereas other CCMs fully use or exceed their quotas. To date, WCPFC has not really discussed transfer of limits, though transfers regularly occur in other RFMOs such as the International Commission for the Conservation of Atlantic Tunas (ICCAT) and the Inter-American Tropical Tuna Commission (IATTC). The United States allows its territories to transfer some of their bigeye limits ${ }^{3}$ to sections of the United States fleet in exchange for funds for fisheries development projects. This has had the benefit of allowing that fleet to continue fishing through the year and has benefited the territories through funds for fisheries development projects. The WCPFC does allow for charters where vessels flagged to one CCM can enter into agreements with second CCM and catch under the charter is attributed to the second CCM. However, it has not always been easy to ensure catch from charters is attributed correctly and there has been some problems with double-counting. Perhaps if the WCPFC had a clear effort or catch transfer mechanism between CCMs participating in the fishery then this would help to ensure that limits are being used efficiently and transparently in a way that everyone is aware of where the catch is occurring.

Some of the struggles in setting limits are also due to issues around allocation of fishing privileges amongst CCMs. The WCPFC Convention lists a variety of elements to be considered in formulating allocations and the specific articles are referenced in paragraph 44 of CMM 2018-01 in discussing the development of a framework for allocating limits - although no prioritization scheme has been agreed upon. Dividing up the WCPO fisheries pie is very contentious particularly since most purse seine fishing in the WCPFC takes places within the EEZs of SIDS whereas much of the effort comes from the fleets of distant water fishing nations. The Commission has avoided making concrete decisions

\footnotetext{
${ }^{3}$ The United States territories do not have bigeye limits in the WCPFC, but the United States government has established domestic limits for each territory.
} 
about allocation to date though they have recognized the need to do so. Paragraph 42 of CMM 2018-01 states, "The limits set out. ... do not confer the allocation of rights to any CCM and are without prejudice to future decisions of the Commission." Many of the Pacific Islands countries are advocating the continuation and expansion of zone-based management, and the PNA has stated it intends to operate a longline VDS system in its members' zones, and it unclear how this will influence the development of future Commission conservation measures. Each Commission member is motivated to protect their interests, and this can result in policies that may not necessarily promote sustainability much less economic efficiency.

Although the WCPFC has not discussed an overall TAC for bigeye, adopting limits and the allocation of those limits will be a focus of the WCPFC in the near-term as CMM 2018-01 contains provisions that state that the Commission will agree to hard limits in the purse seine fishery (catch or effort in the high seas) and longline (bigeye catch) as well as a framework for allocation of those limits by 2020 .

\section{Incentive-Based Approaches to Bycatch Reduction}

The seasonal FAD closures have been effective at maintaining fishing mortality for bigeye tuna. If circumstances for bigeye tuna were to change such that the length of FAD closures become sufficiently long then the cost to the vessels can become prohibitive and incentive-based approaches can lead to lower costs, flexibility in supplying processors, and bycatch reduction. In the following discussion, we explore some incentive-based approaches that could lead to least cost bycatch reduction.

\section{Invest in Methods to Better Estimate Purse Seine Bigeye Catch in Real-Time and Consider Transferable Purse Seine Limits}

To date WCPFC has placed primarily input controls on the purse seine fishery which maintained recent levels of fishing mortality and stock biomass. The WCPFC could consider output controls for the purse seine fishery as they could help ensure catch reductions. However, one key issue preventing the adoption of output controls for bigeye catch in the purse seine fishery is that bigeye catches are difficult to estimate in real-time or near real-time with certainty because they generally represent a very small percentage of the total catch. Additionally, independent verification of landings in multiple countries is difficult and costly. SPC-OFP can adjust CCMs' catch estimates using fishery observer and port sampling information, but generally only months after the fishing year is complete. As reporting and monitoring move to more timely electronic methods, it should be possible to develop schemes that combine logbook and observer data to better estimate bigeye catch in near real-time. These near real-time estimates could be compared to or audited by port samplers as well as cannery receipts.

Is should be noted that the problem of accurately identifying species in tuna catches is not unique to the WCPFC, but also plays out in the other tuna-RFMOs. In fact, the IATTC, the counterpart to the WCPFC in the eastern Pacific, faces many of the same issues and struggles. The IATTC has chosen to manage its fisheries in a similar fashion to the WCPFC, with catch limits for the longline fishery and effort limits for the purse seine fishery. In general, the tactics are similar in that both Commissions adopt command-and-control type provisions. The IATTC has adopted full closure periods instead of FAD closure periods, and has a fixed time area closure for an area of the high seas referred to as the "corralito." At the 91st Extraordinary Meeting of the IATTC in February 2017, the IATTC considered a proposal to have bigeye performance limits that each vessel would have to abide by, but this option was difficult because the IATTC would be responsible for deriving in near-real time vesselspecific catch estimates of bigeye tuna. At some point, reducing the uncertainty in real-time bigeye catch estimates is a critical missing piece to allowing better management of bigeye catch in the purse seine fishery.

If it becomes possible to accurately estimate bigeye catch in real-time or near real-time, the WCPFC might consider developing bigeye catch limits for purse seine vessels as this could likely create direct incentives to reduce bigeye catch and in turn fishing mortality from the purse seine fishery. This limit could be implemented on a by-vessel basis or for a particular fleet. The Commission and/or members could consider allowing transfers of limits or unused portions of limits, called credits, as needed through a credit system so that the purse seine bigeye catch limit would be used efficiently. Some flexibility in landings throughout the year could potentially smooth ex-vessel prices and assure a more steady supply for processors. If bigeye catches can be easily estimated, CCMs could potentially consider invoking some sort of tax or penalty for catching juvenile bigeye or even yellowfin. This tax may not be monetary, but in-kind such as additional days fishing, such as was implemented in the Scottish troll fishery for cod bycatch (Squires and Garcia, 2018).

\section{Effort Incentives}

The WCPFC, other members, or regional organizations could consider initiating fees for FADs (deploying or setting) in the WCPFC area, in effect pricing FAD usage to account for otherwise uncosted ecological impacts and an incentive-based approach. The PNA recently announced their intention to have vessels that fish in their zones pay an additional fee for any FAD sets made in their zones. Most purse seine fishing takes place in PNA waters, and so this could be an effective mechanism to control FAD sets on top of any FAD limits that the Commission adopts. By pricing FAD sets, residual catch of juvenile bigeye (and unpriced bycatch such as oceanic sharks) receives a cost, which is shared among fishers, supply chain firms, and consumers according to their ability to pass on or absorb these costs. This indirect way to price juvenile bigeye (and bycatch) is less effective and efficient than direct pricing of juvenile bigeye catch but is less expensive to implement and more likely to achieve compliance and easier to enforce. The Commission does not currently have a mechanism to enact charges on vessels, but if fees were initiated in other areas such as within other EEZs or on 
the high seas, these fees could be used to support research into ways to improve data estimates or others ways to fund bycatch reduction technologies.

\section{Consumer Preference and Ecolabels}

The WCPFC has a limited ability to affect consumer preference; however, this is another area that could exert greater influence on bigeye catch. Consumer demand for sustainably caught tuna has led several companies in the Western Pacific to pursue certifications such as those offered by the Marine Stewardship Council (MSC) for their free school catch. Some consumers are willing to pay a premium for MSC-certified tuna, and this price premium is theoretically passed down to vessel operators and owners from canneries seeking tuna caught from FAD free sets. The approach could also be implemented through a simple industry standard through supply chain requirements. Market demand for FAD-free tuna could prove to be beneficial for bigeye conservation as purse seine vessels typically catch bigeye in association with FAD sets. If the price premium is sufficiently high, this might further incentivize vessels to catch more tuna without using FADs through a positive incentive-based approach. Currently, only certain markets appear willing to pay a material premium for FAD-free fish and large markets like the United States continue to show limited preference to FAD-free sourced fish (Gutierrez et al., 2016; van Putten et al., 2020, R. Clarke, pers.com.).

\section{Real-Time Spatial Management}

One approach that has successfully reduced bycatch in many fisheries, with potential in the purse seine industry for limiting juvenile bigeye (and bycatch of oceanic sharks and other species) is real-time spatial management (RTSM) implemented under either a co-management or self-governance approach (Hobday and Hartmann, 2006; Little et al., 2015). Should technology improve in the future such that accurate estimates of bigeye tuna are possible, real-time and near real-time information from the electronic sensors of buoys attached to FADs on species density and mix under the FADs could be shared among fishers to incentivize vessels to leave areas and/or set on FADs of high juvenile bycatch. The information can be shared through a private, specialized company to insure data privacy and integrity. RTSM can also integrate this data with real-time biological, oceanographic, and economic data from satellites and remote sensing, and animal tracking and tagging, and using advanced analytical techniques such as machine learning, to either predict key species distributions and/or to indicate real-time "hotspots." Predictions from models can be provided by either private or public bodies as a public good available to all or as a private good only available by subscription (e.g., Turtlewatch).

RTSM needs to be incentivized. Credit systems discussed above, credit systems through reward of extra FAD sets otherwise held in reserve, rebates from FAD pricing, penalties and fines either explicit or implicit through longer closed seasons or fewer allowable sets, are all possibilities.

\section{Deposit-Refund Systems}

Finally, one speculative approach is a deposit-refund system to clear the water of FADs during closed periods, limit ghost FADs, reduce marine debris, and incentivize more "eco-FADs." Deposits are required for each $\mathrm{FAD}$, which is refunded to any party returning the FAD at the end of an open season. More "eco-FAD" designs that reduce bycatch might have lower deposit and refund rates that incentive adoption if there are not RFMO technology standards that mandate such designs. Economic lifetimes of FADs are relatively short due to high rates of physical depreciation, leading to more FADs that receive deposits than those that exist to receive the refund. 'Revenue neutrality' may require higher refund rates.

\section{CONCLUSION}

The Commission's objectives for managing bigeye have shifted over time as stock status changed from one experiencing overfishing prior to 2017 to one that is not experiencing overfishing from 2017 forward. The Commission has adopted a number of CMMs to work toward the different objectives over time, and these have resulted in mainly "commandand-control" type policies for the purse seine and longline fisheries. Evaluations of CMM 2018-01 indicate that the objectives for bigeye may be achieved if recruitment remains at recent levels, but declines in spawning biomass may occur is recruitment levels are more similar to the longterm average (SPC, 2019c). If current approaches for bigeye management become no longer tenable, the WCPFC may want to consider incentive-based approaches that lead to leastcost bycatch reduction and help maintain vessel profitability. The Commission will be challenged to develop a new CMM for tropical tunas, and hopefully bigeye can be managed in ways to meet the Commission's objectives of long-term sustainability whether that be the result of decisions by the Commission, individual CCMs or other regional groups or consumer demand.

\section{AUTHOR CONTRIBUTIONS}

VP wrote most of the manuscript with contributions from DS. Both authors contributed to the article and approved the submitted version.

\section{ACKNOWLEDGMENTS}

The authors would like to thank Raymond Clarke for providing insightful input and to Rini Ghosh and David O'Brien for providing edits to the manuscript. The authors would also like to acknowledge the two reviewers, who provided helpful comments to improve the manuscript. The results and conclusions, as well as any views or opinions expressed herein, are those of the authors and do not necessarily reflect those of NOAA or the Department of Commerce. 


\section{REFERENCES}

Abascal, F., Lawson, T., and Williams, P. (2014). "Analysis of tropical purse seine length data for skipjack, bigeye and Yellowfin tunas," in Proceedings of the Tenth Regular Session of the Scientific Commitee, Majuro, WCPFC-SC10-2014/SA-IP05.

Barret, S. (2016). Coordination vs. voluntarism and enforcement in sustaining international environmental cooperation. Proc. Natl. Acad. Sci. U.S.A. 113, 14515-14522. doi: 10.1073/pnas.1604989113

Barrett, S. (2003). Environment and Statecraft: The Strategy of Environmental Treaty-Making. Oxford: Oxford University Press.

Chan, V., Clarke, R., and Squires, D. (2014). Full retention in tuna fisheries: benefits, costs and unintended consequences. Mar. Policy 40, 213-221. doi: 10.1016/j.marpol.2013.10.016

Dagorn, L., Holland, K., Restrepo, V., and Moreno, G. (2012). Is it good or bad to fish with FADs? What are the real impacts of the use of drifting FADs on pelagic marine ecosystems? Fish Fish. 14, 391-415. doi: 10.1111/j.1467-2979. 2012.00478.x

Davies, N., Hoyle, S., Harley, S., Langley, A., Kleiber, P., and Hampton, J. (2011). "Stock assessment of bigeye tuna in the western and central Pacific Ocean," in Proceedings of the Seventh Regular Session of the Scientific Committe, Pohnpei, WCPFC-SC7-2011/SA-WP-02.

Farley, J., Eveson, P., Krusic-Golub, K., Sanchez, C., Roupsard, F., McKechnie, S., et al. (2017). "Project 35: Age, growth and maturity of bigeye tuna in the western and central Pacific Ocean," in Proceedings of the Thirteenth Regional Session of the Scientific Commitee, Rarotonga, WCPFC-SC13-2017/SA-WP-01.

Gutierrez, N., Defeo, O., Bush, S., Butterworth, D., Roheim, C., and Punt, A. (2016). The current situation and prosepcts of fisheries certification and ecolabelling. Fish. Res. 182, 1-6. doi: 10.1016/j.fishres.2016.05.004

Hanich, Q. (2012). Distributing the bigeye conservation burden in the western and central pacific fisheries Marine Policy. 36, 327-332. doi: 10.1016/j.marpol.2011. 07.008

Harley, S., Davies, N., Hampton, J., and McKechnie, S. (2014). “Stock assessment of bigeye tuna in the western and central Pacific Ocean," in Proceedings of the 10th Regular Session of the Scientific Committee, Majuro, WCPFC-SC10-2014/SAWP-01 rev.1.

Harley, S., Hoyle, S., Williams, P., Hampton, J., and Kleiber, P. (2010). "Stock assessment of bigeye tuna in the western and central Pacific Ocean," in Proceedings of the Sixth Regular Session of the Scientific Committee, Nuku'alofa, WCPFC-SC6-2010/SA-WP-04.

Hobday, A., and Hartmann, K. J. (2006). Near real-time spatial management based on habitat predictions for a longline bycatch species. Fish. Manag. Ecol. 13, 365-380. doi: 10.1111/j.1365-2400.2006.00515.x

Lawson, T. (2014). "Comparison of the species composition of purse-seine catches determined from logsheets, observer data, market data, cannery receipts and port sampling data," in Proceedings of the Tenth Regular Session of the Scientific Committee, Majuro, WCPFC-SC10-2014/ST-WP-02.

Libecap, G. D. (2014). Addressing global environmental externalities: transactions costs considerations. J. Econ. Literature 52, 424-479. doi: 10.1257/jel.52.2.424

Little, A. S., Needle, C. L., Hilborn, R., Holland, D. S., and Marshall, C. T. (2015). Real-time spatial management approaches to reduce bycatch and discards: experiences from Europe and the United States. Fish Fish. 16, 576-602. doi: $10.1111 /$ faf. 12080

McKechnie, S. (2014). "Analysis of longline size frequency data for bigeye and yellowfin tunas in the WCP," in Proceedings of the Tenth Regular Session of the Scientific Committee, Majuro, WCPFC-SC10-2014/SA-IP-04.

McKechnie, S., Pilling, G., and Hampton, J. (2017). "Stock assessment of bigeye tuna in the western and central Pacific Ocean," in Procceedings of the Thirteenth Regular Session of the Scientific Committee, Rarotonga, WCPFWCPFC, C.,SC13-2017/SA-WP-05: 149.

Miyake, M. (2007). "Factors affecting recent developments in tuna longline fishing capacity and possible options for management of longline capacity", in Methodological Workshop on the Management of Tuna Fishing Capacity: Stock
Status, Data Envelopment Analysis, Industry Surveys and Management Options, eds W. H. Bayliff and J. Majkowski (La Jolla, CA: FAO Fisheries Proceedings).

Norris, A. (2015). Fishy business: the high seas boarding and inspection regime in the western and central pacific ocean. Ocean Dev. Intern. Law 46, 331-344. doi: 10.1080/00908320.2015.1089746

Pilling, G., Williams, P., Hampton, J., and Harley, S. (2013). "Analysis of the implementation and effectiveness of key management measures for tropical tunas," in Proceedings of the Ninth Regular Session of the Scientific Committee, Pohnpei, WCPFC-SC9-2013/MI-WP-01 Rev 2.

SPC, (2014). "Evaluation of CMM 2013-01," in Proceedings of the Eleventh Regular Session of the Commission, Apia, WCPFC11-2014-15.

SPC, (2015). "Evaluation of CMM 2014-01 for Bigeye Tuna," in Proceedings of the Twelfth Regular Session of the Commission, Kuta, WCPFC12-2015-12_Rev1.

SPC, (2016). "Evaluation of CMM 2015-01 for Bigeye Tuna," in Proceedings of the Thirteenth Regular Session of the Commission, Fiji, WCPFC13-2016-15.

SPC, (2017). "An evaluation of the management options for purse seine and longline fisheries defined by the TT CMM intersessional meeting," in Proceedings of the Fourteenth Regular Session of the Commission, Manila, WCPFC14-2017-10_rev1.

SPC, (2018). "Evaluation of CMM 2017-01 for Bigeye Tuna with Additional Evaluations for Skipjack and Yellowfin Tuna," in Proceedings of the Fifteenth Regular Session of the Commission, Honolulu, US WCPFC15-2018-12_rev2.

SPC, (2019a). "Catch and effort tables on tropical tuna CMMs," in Proceedings of the Sixteenth Regular Session of the Commission, Port Moresby, WCPFC16-2019IP05_rev1.

SPC, (2019b). "Estimates of annual catches in the WCPFC statistical area," in Proceedings of the Fifteenth Regular Session of the Scientific Committee, Pohnpei, WCPFC-SC15-2019/ST IP-1: 33.

SPC, (2019c). "Evaluation of CMM 2018-01 for Tropical Tuna," in Proceedings of the Sixteenth Regular Session of the Commission, Port Moresby, WCPFC162019-17.

SPC, (2019d). Tuna Fishery Yearbook 2018. Pohnpei: Western and Central Pacific Fisheries Commission.

Squires, D., and Garcia, S. (2018). The least-cost biodiversity impact mitigation hierarchy with a focus on marine fisheries and bycatch issues. Conserv. Biol. 32, 989-997. doi: 10.1111/cobi.13155

Tidd, A., Pilling, G., and Harley, S. (2015). "Examining productivity changes within the tropical WCPO purse seine fishery," in Proceedings of the Eleventh Regular Session of the Scientific Committee, Pohnpei, WCPFC-SC11-2015/MI-WP-06.

van Putten, I., Longo, C., Arton, A., Watson, M., Anderson, C., and Himes -Cornell, A. (2020). Shifting focus: the impacts of sustainable seafood certification. PLoS One 15:233237. doi: 10.1371/journal.pone.0233237

WCPFC, (2017). "Summary report," in Proceedings of the Thirteenth Regular Session of the Scientific Committee, Rarotonga.

Williams, P., and Reid, C. (2019). "Overview of tuna fisheries in the Western and Central Pacific Ocean, including economic conditions - 2018," in Proceedings of the Fifteenth Regular Session of the Scientific Committee, Pohnpei, WCPFCSC15-2019/GN-WP-1: 69.

Williams, P., and Terawasi, P. (2016). "Overview of tuna fisheries in the Western and Central Pacific Ocean, including economic conditions - 2015," in Proceedings of the 12th Regular Session of the Scientific Committee, Bali, WCPFWCPFC, C.,-SC12-2016/GN WP-1 rev.3: 69.

Conflict of Interest: The authors declare that the research was conducted in the absence of any commercial or financial relationships that could be construed as a potential conflict of interest.

Copyright (C) 2020 Post and Squires. This is an open-access article distributed under the terms of the Creative Commons Attribution License (CC BY). The use, distribution or reproduction in other forums is permitted, provided the original author(s) and the copyright owner(s) are credited and that the original publication in this journal is cited, in accordance with accepted academic practice. No use, distribution or reproduction is permitted which does not comply with these terms. 